\title{
WANUA NUSANTARA: PRAKTIK PEMBUMIAN NILAI-NILAI PANCASILA DI KALANGAN GENERASI MUDA
}

\author{
Abd. Mu'id Aris Shofa ${ }^{1 *}$, Abdul Kodir ${ }^{2}$, Mifdal Zusron Alfaqi ${ }^{1}$, Arif Subekti ${ }^{3}$ \\ abd.muid.fis@um.ac.id \\ 1Jurusan Hukum dan Kewarganegaraan, Fakultas Ilmu Sosial, Universitas Negeri Malang \\ 2Jurusan Sosiologi, Fakultas IImu Sosial, Universitas Negeri Malang \\ ${ }^{3}$ Jurusan Sejarah, Fakultas IImu Sosial, Universitas Negeri Malang \\ Diterima 28 Februari 2019, dipublikasikan 30 April 2019
}

\begin{abstract}
Abstrak
Tujuan dari penulisan artikel ini adalah untuk mengetahui kendala-kendala apa saja yang dihadapi oleh pemuda di kelurahan sisir dalam menanamkan nilai-nilai Pancasila dan untun mengetahui upaya yang dapat dilakukan untuk memotivasi pemuda dalam menanamkan nilai-nilai Pancasila. Metode pelakasanaan yang digunakan adalah pertama, analisis situasi masyarakat dengan dua tahapan yaitu khalayak sasaran dan menentukan bidang permasalahan yang akan dianalisis. Setelah itu ada rencana pemecahan masalah dan rencana pelaksanaan kegiatan serta yang terakhir yaitu evaluasi kegiatan dan hasil, adapun lokasi kegiatan di kelurahan sisir kecamatan batu kota batu, hasil dari pengabdian ini menunjukan bahwa ketidak tahuan akan realitas keindonesian yang sangat multicultural dan penuh keberagaman, sehingga membuat para pemuda belum mampu secara konkrit untuk mengimplementasikan nilai-nilai Pancasila. Upaya pemberian pelatihan kader Pancasila mempunyai dampak yang sangat positif bagi pemuda khususnya di kelurahan sisir kecamatan batu kota batu sehingga mampu mengimplementasikan nilai-nilai Pancasila dalam praktik kehidupan sehari-hari.
\end{abstract}

Kata Kunci: Pelatihan Kader, Pembumian, Pancasila

\section{PENDAHULUAN}

Multikulturalitas bangsa merupakan realitas dalam komunitas indonesia yang tak mungkin dipungkiri dan dihindari, bangsa Indonesia yang terdiri dari ribuan pulau, ratusan bahasa, suku, bangsa dan agama. Kondisi ini merupakan berkah dan hikmah apabila kita mampu mengaransemennya dalam sebuah keterpaduan yang menghasilkan keindahan dan kekuatan, tetapi juga bisa menjadi musibah disintregasi bangsa manakala multikulturalitas itu tidak terakomodasi dengan baik. Oleh karena itu, dapat dimengerti jika desain dari pendirian bangsa dan negara kesatuan republik Indonesia adalah negara yang bersatu, berdaulat adil dan makmur, untuk mewujudkan sebuah negara kebangsaan "yang bersifat demokratis dan yang hendak menyelenggarakan keadilan sosial dan perikemanusiaan". Sebab para pendiri bangsa Indonesia ini meyakini bahwa hanya melalui sebuah negara kebangsaan, demokrasi, keadilan sosial, dan perikemanusiaan (HAM) yang kemudian dipadu dengan kesadaran berketuhanan Yang Maha Esa, kemajemukan pluralitas bangsa ini bermakna positif. Seperti cuplikan pidato Bung Karno pada tanggal 1 juni 1945, "Negara Indonesia bukan satu negara untuk satu orang, bukan satu negara untuk satu golongan, walaupun golongan kaya. Tetapi kita mendirikan negara "semua buat semua, satu buat semua, semua buat semua.

Kondisi realitas masyarakat Indonesia sekarang ini masih ada anggapan dari sebagian kelompok masyarakat bahwa perbedaan itu adalah musuh yang harus dikalahkan, perbedaan itu adalah suatu ancaman yang harus dihilangkan. Kelihatannya terlalu berlebihan, keberagaman suku, agama, budaya, ras dan antar golongan bukanlah suatu ancaman dan potensi konflik yang berakibat terjadinya disintegrasi bangsa. Tetapi justru perbedaan itu adalah jalan menuju pengintegrasian bagi bangsa Indonesia. Artinya, kondisi masyarakat yang sangat multikultural itu bisa mendorong masyarakat untuk secara otomatis melakukan pengintegrasian secara menyeluruh. Sejarah sudah membuktikan bahwa bangsa Indonesia dibentuk berdasarkan atas perbedaan-perbedaan yang membentang dari sabang sampai merauke, dan tidak ada sedikitpun kekhawatiran akan terjadinya suatu disintegrasi bangsa. 
Disintegrasi bangsa terjadi ketika diantara masyarakat tidak dapat dan tidak mampu mengaransemen perbedaan kemajemukan dan multikultural itu dengan baik. Selain itu anggapan adanya kelompok mayoritas dan minoritas, superior dan inferior harus dihilangkan.

Untuk itu diperlukan suatu pemahaman dan kemauan mengapresiasi keberagaman multikultural dalam masyarakat dan kebudayaan Indonesia bahwa pihak mayoritas atau superior dalam mempertahankan eksistensinya, baik langsung maupun tidak memerlukan sumbangan pihak minoritas dan inferior. Dikotomi mayoritas-minoritas, superior-inferior pada aspek multikulturalisme bisa menjadi tragedi besar, bila ditumpangi dengan muatan politik-ideologis ataupun ketimpangan dalam kesempatan kinerja ekonomi (Kusumohamidjojo, 2000). Dengan demikian, pembangunan masyarakat Indonesia yang bhinneka memerlukan kesadaran penuh tentang ketunggalan dalam keberagaman. Ini merupakan ide tentang penegakan kesatuan Indonesia berdasarkan upaya mengapresiasikan keanekaragaman masyarakat dan kebudayaan Indonesia. Keaneragamanan masyarakat dan kebudayaan Indonesia sesungguhnya bukan masalah baru. Menurut Franz Magnis-Suseno (2010) bahwa sejak sebelum berdirinya sebagai negara merdeka, Indonesia sudah menghadapi persoalan besar yang berkaitan dengan keanekaragaman kebudayaan dan agama, yaitu pertentangan dalam penetapan sila pertama dalam Pancasila antara kelompok nasionalis dan kelompok agama. Persoalan ini menjadi semakin besar seiring dengan perkembangan zaman dan dinamika sejarah yang menyertainya.

Masalah kebhinnekaan itu perlu dibedah secara tuntas, agar masyarakat Indonesia tidak terbuai dan hanyut dalam slogan, seolah-olah keanekaragaman itu lebih merupakan berkah dan bukan pekerjaan rumah. Hal ini dipahami oleh banyak orang Indonesia yang berpikir jernih dan menyadari beratnya tantangan masa depan negara-bangsa ini. Dalam kerangka inilah letak relevansi multikulturalisme untuk membahas masalah kebhinnekaan masyarakat Indonesia. Tegasnya, bangsa Indonesia yang multikultural mutlak harus dipandang dari kacamata multikulturalisme, sebagaimana dikemukakan Franz Magnis-Suseno (2005) bahwa Indonesia hanya dapat bersatu, bila keanekaragaman yang menjadi kenyataan sosial dihormati. Artinya, penegakan kesatuan Indonesia bukan hendak menghilangkan identitas setiap komponen bangsa, tetapi harapannya agar semuanya menjadi warga negara Indonesia tanpa merasa terasing. Sikap saling menghormati identitas masingmasing dan kesediaan untuk tidak memaksakan pandangan sendiri tentang yang baik kepada siapapun merupakan syarat keberhasilan masa depan Indonesia. Untuk itu, diperlukan transformasi kesadaran multikulturalisme menjadi identitas nasional, integrasi nasional, dan menempatkan agama menjadi fondasi kesatuan bangsa. Dari latar belakang diatas maka hal yang akan di kaji adalah, bagaimana masyarakat khususnya pemuda melihat keberagaan sebagai semangat persatuan dan bagaimana pemuda membumikan nilai-nilai Pancasila dalam kehidupan sehari-hari di Kelurahan Sisir Kecamatan Batu Kota Batu.

\section{METODE PELAKSANAN}

Metode pelaksanaan kegiatan yang digunakan dalam pengabdian ini adalah menggunakan bebarapa tahapan yang pertama adalah menentukan khalayak sasaran dimana Sasaran kegiatan ini adalah masyarakat atau pemuda karang taruna yang terdapat di Kelurahan Sisir Kecamatan Batu. Pemilihan dan penetapan sasaran Pelatihan Kader Pancasila. Tahap selanjutnya adalah analisis bidang permasalahan dimana mayoritas pemuda kelurahan sisir banyak yang pandai namun kesadaran akan jiwa solidaritas dan pentingnya implementasi nilai pancasila masih sangat kurang. Sehingga selama ini semangat gotong royong dan solidaritas dalam diri pemuda belum mampu terwujud dengan maksimal

\section{Rencana Pemecahan Masalah}

Permasalahan yang sudah diidentifikasi perlu dipecahkan dan sekaligus mencapai tujuan (kondisi baru) yang telah ditetapkan. Semuanya itu perlu direncanakan dalam tahap ini, yang terdiri antara lain: (1) Analisis Kebutuhan, (2) Pelaksanaan Kegiatan (Pelatihan Kader Pancasila Bagi Pemuda Untuk Meningkatkan Ketahanan Nasional"), (3) Refleksi / Rekomendasi dan (4) Pelaporan.

Pertama, analisis kebutuhan dapat dilakukan dengan mengumpulkan data atau informasi dari observasi, wawancara mendalam, dan studi dokumentasi pada pemuda Karang taruna dikelurahan 
Sisir berkaitan dengan kendala penanaman nilai-nilai pancasila selanjutnya dijadikan bahan yang akan dianalisis dalam pelatihan kader pancasila. Narasumber menyusun makalah atau modul tentang strategi penanaman nilai-nilai pancasila pada diri pemuda. Dalam tahapan ini juga akan dibuat atau disusun jadwal pelaksanaan kegiatan pelatihan.

Kedua, pelaksanaan kegiatan adalah dimulai dengan pemberian materi yang disampaikan oleh narasumber pertama berkaitan dengan makna dari sila-sila pancasila dan bagaimana cara mengimplementasikannya kedalam kehidupan bermasyarakat. Kemudian, kegiatan akan dilanjutkan dengan penyampaian materi oleh narasumber kedua berkaitan dengan strategi penanaman nilai pancasila pada pemuda guna membangun semangat jiwa yang sesuai dengan pancasila.

Ketiga, refleksi / rekomendasi adalah peserta beserta narasumber memberikan refleksi, komentar dan rekomendasi atas semua materi yang telah dipelajari bersama. Termasuk mencatat halhal yang perlu diperbaiki atau yang harus dipertahankan dalam pengimplementasiannya secara langsung di lapangan.

Keempat, pelaporan merupakan tahap akhir dari pelaksanaan pengabdian, yaitu dilakukan persiapan perangkat pelaporan sesuai dengan jadwal yang ditentukan.

\section{HASIL DAN PEMBAHASAN}

\section{Pembumian Nilai-nilai Pancasila dalam Kehidupan Sehari-hari}

Indonesia adalah negara yang multikultural yang berdasarkan atas multi etnik, multi bahasa, multi agama dan multi budaya. Jika kenyataan ini tidak bisa diolah dan di aransemen dengan baik, maka akan bisa menimbulkan kekacauan yang bisa membahayakan persatuan dan kesatuan bangsa Indonesia. Hal ini sudah sering terlihat dalam konteks kehidupan masyarakat kita dengan banyaknya konflik-konflik yang terjadi baik di poso, ambon, papua, aceh dan daerah-daerah lainnya. Akan tetapi jika bangsa indonesia mampu mengelola perbedaan-perbedaan itu dengan baik maka itu menjadi satu kekuatan besar yang tidak tertandingi. Bangsa Indonesia memperoleh kemerdekaan melalui semangat persatuan dan kesatuan yang kuat.

Ideologi memberi bangsa Indonesia hal-hal yang ideal untuk diyakini akan kebenaranya, fungsi penting dari ideologi adalah membentuk identitas kelompok yang majemuk dan multikultural. Ideologi memiliki kecenderungan untuk memisahkan kita (ingrouop) dari mereka (outgroup). Dengan demikian maka ideologi berfungsi mempersatukan. Apabila dibandingkan dengan agama, agama juga berfungsi mempersatukan manusia dari berbagai kalangan yang majemuk dengan berbagai pandangan hidup masing-masing, bahkan mempersatukan manusia dari berbagai negara yang diikat dengan ideologinya masing-masing. Sebaliknya ideologi mempersatukan orang dari berbagai agama dan untuk mengatasi konflik atau ketegangan sosial.

Belajar dari semangat para pemuda pada 1928 yang telah mampu mempelopori persatuan dan kesatuan bangsa, maka kita sebagai generasi penerus bangsa meskipun dalam berbagai kesulitan dan keprihatinan masih mewarnai berbagai aspek kehidupan berbangsa dan bernegara. Seharusnya kita mampu mempertahankan dan terus memperjuangkan semngat persatuan dan kesatuan bangsa yang telah diwariskan para pendahulu kita dengan tetap berpegang teguh pada semboyan Bhineka Tunggal Ika dan ideologi Pancasila. Pemuda khususnya di Kelurahan Sisir Kecamatan Batu telah mampu dan bias belajar dari peristiwa sejarah bangsanya bagaimana melihat realitas dalam kehidupan sehari-hari sehingga dalam praktiknya tidak ada pertentangan dengan nilai-nilai Pancasila.

Pancasila adalah common platform sekaligus rasionalitas publik di mana keberagaman dari budaya, agama, etnis dan ras bertemu dan disana terbentuk suatu negara bangsa. Di dalam negara bangsa kita identitas kedaerahan, identitas keagamaan semua merasa terwakili. Tidak berlaku yang namanya mayoritas minoritas atau superior inferior karena semua tertampung dengan sama. Demokrasi yang berlaku bukanlah demokrasi mayoritarian tetapi adalah demokrasi Pancasila (Oentoro, 2010). Adat istiadat yang beragam pun juga dihormati dan di abadikan dalam semangat Bhineka Tunggal lka.

Pancasila adalah suatu sistem nilai yang digali dari nilai dan identitas bangsa yang berdasarkan atas kehidupan sosial, kultural, dan religiusitas yang beragam dan majemuk. Nilai-nilai tersebut tidak dapat dipisah-pisahkan. Kerukunan umat beragama, keberagaman etinistas, budaya dan bahasa akan 
terjaga apabila kita dapat menjaga konsistensi dan komitmen terhadap nilai-nilai Pancasila. Fakta kemajemukan dan multikulturalitas dalam masyarakat harus dihormati, dilestarikan, dan dikembangkan berdasarkan atas nilai-nilai luhur yang terkandung dalam sila Pancasila.

\section{KESIMPULAN}

Pada akhirnya dapat dipahami bahwa untuk mewujudkan kesatuan Indonesia dapat ditempuh setidak-tidak tiga upaya berikut. Pertama, mentransformasikan kesadaran multikulturalisme menjadi identitas nasional dengan bertumpu pada penghargaan terhadap kemajemukan, hetrogenitas dan pluralitas masyarakat Indonesia. Untuk itu Bhinneka Tunggal lka sebagai teks ideal senantiasa perlu dibaca ulang pada setiap zaman karena pada prinsipnya identitas tidak pernah final. Kedua, membangun integrasi nasional yang berbasis multikulturalisme dengan mendorong kesadaran masyarakat menggunakan hak konstitusinya dalam berkumpul, berserikat, dan berpendapat guna memperjuangkan hak-hak keadilan, kebebasan, kesetaraan, serta berpartisipasi aktif dalam pembangunan.

Pemuda-pemuda di Kelurahan Sisir Kecamatan Batu Kota Batu telah mampu mempraktikan dan mengimplementasikan nilai-nilai Pancasila dalam kehidupan sehari-hari, sehingga Pancasila tidak hanya dimaknai sebagai slogan dan dihafalkan saja tetapi telah mampu diwujudkan dalam kehidupan nyata. Sehingga dengan adanya hal tersebut sungguh layak proses sepeerti itu dijadikan role model atau contoh tentang bagaiman pembumian nilai-nilai Pancasila khususnya pada diri pemuda dan pada wilayah yang sangat multikultural. Hal ini menjadi sangat penting untuk diperhatikan mengingat saat ini masih banyak orang salah menafsirkat tentang perbedaan atau multicultural sebagai suatu ancaman, hambatan, sehingga harus dimusnahkan dan dihilangkan dengan cara apapun bahkan kekerasan sekalipun.

Pemuda-pemuda di keluarahan sisir kota batu telah mampu mengajarkan kepada semua pihak tentang bagaiaman memahami Pancasila tidak cukup secara verbalis atau hafalan saja, tetapi sudah masuk keranah denotatif atau praktik dan implementasi dalam kehidupan sehari-hari. Apa yang mereka terapkan juga tidak terlepas dari apa yang telah dilakukan oleh tim pengabdian masyarakat yang telah mendatangkan pakar Pancasila yaitu kepala Pusat Pengkajian Pancasila universitas Negeri Malang untuk memberikan pemahaman dan pelatihan terkait dengan praktik pembumian nilai-nilai Pancasila.

\section{UCAPAN TERIMA KASIH}

Dengan berkahirnya kegiatan pengabdian kepada masyarakat di keluarahan sisir kecamatan batu kota batu ini, tidak lupa kami sampaikan ucapan terimakasih yang sebesar-besarnya kepada semua pihak yang telah mendukung dan membantu menyukseskan kegiatan ini. Pertama, Universitas Negeri Malang yang telah meberikan bantuan dana pengabdian PNBP sehingga kegiatan ini bisa berjalan lancer; kedua, pemuda karang taruna keluarahan sisir yang ikut berpartisipasi dan mampu menerima dengan baik semua materi yang disampaiakan oleh pemateri.

\section{DAFTAR PUSTAKA}

Budiman, Hikmat (ed), 2005, Hak Minoritas Dilema Multikulturisme di Indonesia, Jakarta: Yayasan Interseksi/The Interseksi Foundation.

Hutington, Samuel P., 2003, Benturan Antarperadaban dan Masa Depan Politik Dunia, Yogyakarta: Qalam.

Hefner, Robert W., 2007, Politik Multukulturalisme: Menggugat Realitas Kebangsaan, Yogyakarta: Kanisius.

Kusumohamidjojo, Budiono, 2000, Kebhinnekaan Masyarakat Indonesia: Suatu Problematik Filsafat Kebudayaan, Jakarta: PT. Grasindo.

Nurkhoiron, M., 2007, "Minoritisasi dan Agenda Multikulturalisme di Indonesia: Sebuah Catatan Awal", dalam Hak Minoritas Multikulturalisme dan Dilema Negara Bangsa, diedit oleh Marsudi Noorsalim, Jakarta: Yayasan Interseksi/The Interseksi Foundation.

Oentoro, Jimmy., 2010, Indonesia Satu, Indonesia Beda, Indonesia Bisa: Membangun Bhineka Tunggal Ika di Bumi Nusantara, Jakarta: Kompas Gramedia. 
Parekh, Bhiku., 2007, Rethinking Multikulturalism Keberagaman Budaya dan Teori Politik, Yogyakarta: Kanisius.

Sparringa, Daniel. 2006. "Multikulturalisme Indonesia: Nilai-nilai Baru untuk Indonesia Baru (sebuah Jawaban terhadap Kemajemukan)". Makalah disampaikan dalam seminar tentang "Pendidikan Nilai-nilai Kehidupan Ditinjau dari Berbagai Perspektif IImu" yang diselenggarakan oleh Universitas Atmajaya, Jakarta, 18 November 2006.

Susetiawan., 2008, Pluralitas dan Integrasi Sosial Dalam Masyarakat Multicultural, dalam Spiritualitas Multikultur Sebagai Landasan Gerakan Sosial Baru, Yogyakarta: Kanisius.

Suseno, Franz Magnis., 2005, Berebut Jiwa Bangsa, Jakarta: Kompas.

Tilaar, H.A.R., 2004, Multikulturalisme Tantangan-tantangan Global Masa Depan dalam Transformasi Pendidikan Nasional, Jakarta: Grasindo. 